\title{
Adult-onset myasthenia gravis
}

INSERM

\section{Source}

INSERM. (1999). Orphanet: an online rare disease and orphan drug data base. Adultonset myasthenia gravis. ORPHA:391490

Acquired myasthenia gravis (MG) is an autoimmune disorder of the neuromuscular junction characterized by fatigable muscle weakness with frequent ocular signs and/or generalized muscle weakness, and occasionally associated with thymoma (see this term). 